\title{
An Evaluation of the Mathematics Foundation Course in Sultan Qaboos University: Does High School Performance Matter?
}

\author{
M. Mazharul Islam*, Asma Al-Ghassani \& Ahmed Y. S. Al-Hadhrami
}

\author{
Department of Mathematics and Statistics, Sultan Qaboos University, P.O. Box 36, PC 123, \\ Al-Khoud, Muscat, Sultanate of Oman, *Email: mislam@squ.edu.om.
}

\begin{abstract}
Although the mathematics foundation program was introduced in Sultan Qaboos University (SQU) half a decade ago, there has been no evaluation or assessment of the program. The aim of this study was to evaluate the students' performance in the Mathematics foundation course in SQU and to examine the predictive value of a student's high school performance for success in the math foundation course. The study considered a sample of 551 students who took the math course (MATH2107) during 2014 Spring semester. More than 95\% of the students were admitted to SQU with a high school score of 80 and above. The analysis revealed that, in general, female students were admitted to SQU with a significantly higher average high school score than the male students. The findings indicate a very unsatisfactory performance of the students in the mathematics foundation course as the mean GPA was 1.66 and more than half (59\%) of the students obtained a GPA less than 2 (i.e. below grade C), of which $14 \%$ failed and $35 \%$ obtained grade D. Female students outperformed male students in the mathematics course. High school mathematics performance, gender and cohort of students were identified as significant predictors of success in the mathematics foundation course. To increase the success rate of the mathematics course, the high school curriculum needs to be aligned with the University standards and the admission authority should continue to give more attention to high school mathematics scores along with overall high school performance while making admission decisions for the College of Science in SQU.
\end{abstract}

Keywords: Predict; Foundation; High school score; Sultan Qaboos University, Oman.

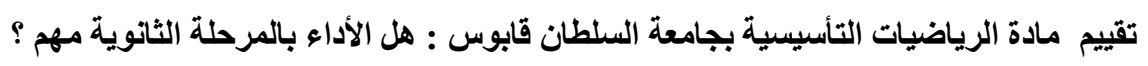

محمد مزهرال اسلام ، أسماء الغساني وأحمد الحضرمي

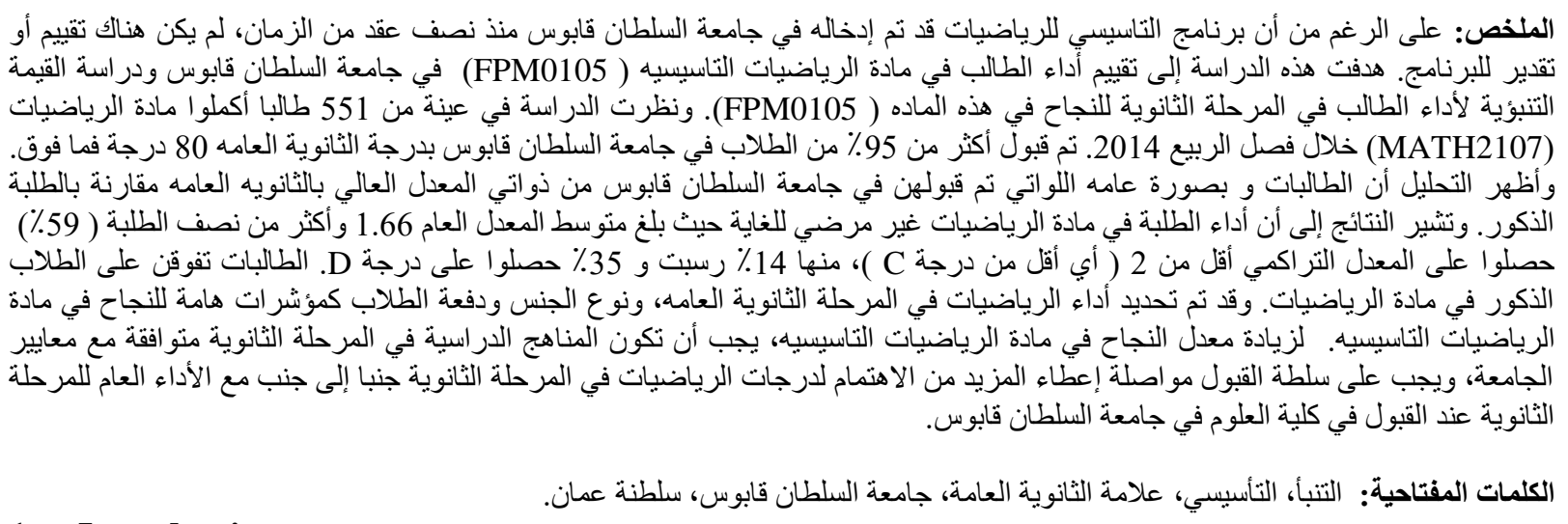

\section{Introduction}

$\mathbf{T}$ The massive expansion of higher education across the world is one of the important development features of our time. The increase in the number of students as well as in that of public and private higher educational institutions, has been associated with an enormous increase in the international mobility of the students over the 
last few decades [1,2]. A profound change in the educational system and concern about the quality of higher education and its standardization has also emerged as an issue [3]. At the same time, many new systems have been introduced for academic standardization and quality control in higher education. The introduction of academic foundation programs (also called preparatory programs) by a growing number of higher education institutions across the globe is one such new program. These programs are typically for those high school graduates who lack necessary skills in English, Mathematics and Information Technology (IT) at the time of entering higher education institutions, and they have become especially prevalent in today's world of internationalization and cross-border academic mobility. In some countries, such as in Britain, international foundation programs (IFPs) exist alongside a range of other university preparatory programs that are offered primarily to domestic students. The IFP is offered not only for improving the linguistic ability of a student, but also to bridge the gap between the British 13year pre-university school system and the 12-year system common to a majority of education systems around the world. Additionally, IFPs are designed to help students meet minimum academic requirements for entry into an undergraduate degree program as well as to prepare them culturally for life and study in a new study environment.

In this era of globalization, the dominance of the English language as a medium of higher education, research and trade is undeniable. It is now a common phenomenon in almost all universities in non-English speaking countries, where courses are mostly taught in English in place of their native languages. In the Middle Eastern countries including the Sultanate of Oman, universities and higher educational institutions teach courses mostly in English in place of their native language Arabic, which is the language of instruction from primary to secondary school level. As a result, students admitted into universities and higher educational institutions are facing language difficulties. It has also been observed that, globally, students entering higher educational institutions do not have sufficient mathematical skills or mathematical background to deal with their first year mathematics courses, and because of this, universities and colleges have seen huge failure and dropout rates [4, 5]. The problem is particularly severe in Oman [6]. Students are also facing IT problems in the higher educational institutions. Thus, to bridge the language, mathematics and IT gaps, most Middle Eastern universities have introduced a preparatory program of English Language, Mathematics and IT which is known as a Foundation Program (FP). The main objective of these programs is to create an atmosphere conducive to a smooth transition from the secondary school to the university.

In 2009, the ministry of Higher Education in Oman released a decision about introducing a foundation program (FP) in all private and public universities and colleges. The program became a mandatory introduction to study in all universities and higher educational institutions. Following that directive, Sultan Qaboos University (SQU), the only public university and the premier institution for higher education in Oman, introduced a FP in the 2010/2011 academic year. The main objective of the programme is to achieve the required educational goals set by the Omani Authority for Academic Accreditation [7]. Within Oman's tertiary education system, the FP is now playing a key role in preparing secondary school graduates for further study by upgrading their English, Mathematics, Computing and General Study Skills [8, 9].

In the Mathematics component of the FP at SQU, particularly in science based colleges, courses are offered at two levels: basic and advanced. To decide the level of mathematics to be offered to a student, a placement test and an exit test are conducted prior to the beginning of the semester. The Basic Mathematics course (i.e.FPMT0101) is offered to those students who do not pass the placement test, while the Mathematics for Sciences course (i.e. FPMT0105) is offered to those who do not pass the exit test. This study is concerned with performance on the FPMT0105 course. The main objective of the course is to prepare the students for calculus and higher mathematics. Its primary topics cover basic mathematics, elementary functions (polynomial, rational, exponential, logarithmic, and trigonometric) and their various applications in solving real world problems.

Although the FP in SQU has been running for the last six years, to our knowledge, there has been no statistical evaluation or assessment of the program performance and how far it is predicting a student's academic success in their degree program. Since mathematics is a key course in the FP, the main objectives of this study are to evaluate students' performance in the FPMT0105 course and to determine how far a student's high school performance can predict success in the foundation mathematics course.

The study findings are expected to provide valuable information and guidelines for the concerned authority and SQU administration, for further improvement of quality of education at both secondary and undergraduate level. The study is expected to bridge the research gap regarding the performance of students of the FP in Oman, and thus may serve as a pilot study for future research to be conducted in this area.

\section{Literature Review}

Over the last century or more, many attempts have been made to identify the predictors of college grades and performance. Most of this research has primarily focused on the predictive power of cognitive factors of students such as high school performance (i.e., high school grades) and scores on standardized tests, such as the American College Testing Program's Assessment (ACT) and the College Board's Scholastic Aptitude Test (SAT) [10,11]. Generally, these studies have found that high school performance and standardized test scores were the most important predictors of success in college and suggested that these cognitive factors could be used to make accurate and appropriate admission and placement decisions for students [12-19]. Traditionally, cognitive factors 


\section{MAZHARUL ISLAM ET AL}

such as high school achievement score, SAT or ACT are widely considered as admission criteria by most higher education institutions in the majority of countries. Some institutions, such as SQU, use only the high school achievement scores, while others use both high school scores and standardized scores (SAT or ACT) to select students [20-23].

A significant body of literature suggests that high school performance is the best predictor of success in undergraduate studies and has more predictive power than the standardized tests or any other factor [24-29]. Some studies have emphasized that the academic performance of the undergraduate students in any college or university depends not only on cognitive factors but also on non-cognitive factors (e.g., teaching and institutional quality, students' motivation and so on) and demographics (e.g., gender, ethnicity, location) [30,31]. Studies have also found that students' non-cognitive characteristics, such as educational aspirations, study habits, and motivation, as well as their involvement in extra curriculum activities, are significantly related to their success in college [30, 32].

Studies have shown that students who took more mathematics courses at high school level performed better in college education and obtained higher scores in standardized tests of mathematics as well as college admission tests $[33,34]$. The stronger the background in mathematics which students achieved in high school, the more likely they were to earn college degrees [16, 35, 36]. Adelman [16] observed that students who took a mathematics course beyond algebra in high school were two times more likely to complete their bachelor's degree without significant delays in the United States of America.

Mathematical knowledge is important to the modern world. It facilitates understanding of the wide range of problems of the 21 st century. For centuries, mathematics has helped us in solving the secrets of nature since modern scientific thinking was formed with mathematical concepts, and scientific concepts are interconnected by the rules of mathematics. Thus, mathematics is considered to be the language of science [37]. With this in mind, educational institutions teach basic mathematics to their students [38].

\section{Data and Methodology}

The data for the study was obtained from the student database maintained by the Deanship of Admission and Registration (A \& R) office of SQU. The sample comprised 551 students who took the mathematics foundation course FPMT0105 during Spring 2014. The course was taught by instructors from the Foundation Program Unit under the supervision of the Department of Mathematics and Statistics, College of Science, SQU. The final grade in FPMT0105 of the 551 students along with their gender, cohorts, high school mathematics scores, high school scores and college of study were obtained from the archive of the A \& R office. Students' grades in FPMT0105 were recorded on a 4 point scale using letter grades $\mathrm{A}=4, \mathrm{~A}-=3.7, \mathrm{~B}+=3.3, \mathrm{~B}=3.0, \mathrm{~B}-=2.7, \mathrm{C}+=2.3, \mathrm{C}=2.0, \mathrm{C}$ $=1.7, \mathrm{D}+=1.3, \mathrm{D}-=1.0$ and $\mathrm{F}=0.0$. The raw scores (out of 100) of FPMT0105 were also available. Data was obtained from students' records as an Excel spreadsheet and then imported into SPSS for statistical analysis.

The study considered the performance of the FPMT0105 course as an outcome or dependent variable, while gender, cohort of study, college of study, high school mathematics score and overall high school scores were considered as predictors or independent variables. The overall high school scores included mathematics scores. Both descriptive and inferential statistics were used for data analysis. Descriptive statistics were computed for all key variables. Inferential statistics techniques involved correlation analysis, cross tabulation and chi-square test, analysis of variance (ANOVA) and multiple regression analysis.

For correlation analysis, we employed both product-moment and 'biserial' correlation coefficients, because some of our variables (e,g. gender, college) are categorical variables. In 1909, Karl Pearson (39) developed the biserial correlation coefficient as a special case of Pearson's product-moment correlation. The product-moment correlation is applied when two variables are quantitative (e.g. GPA and high school scores) and measured either in ratio or interval scale, whereas in the case of biserial correlation one of the variables is measured on a dichotomous scale (e.g. gender: male/female) using a numeric code. The word biserial refers to the separate sets of values of the quantitative variable which are associated with the two values, say 0 and 1 , of the dichotomous variable. Biserial correlation is a widely used statistical technique in social research and biostatistics. In correlation analysis, we have also considered the R-squared statistic (also called co-efficient of determination). In the case of simple linear correlation, the R-squared statistic is simply the square of the simple correlation coefficient $\mathrm{r}$, indicating the proportion of variation in the performance of FPMT0105 explained by the predictors.

The goal of multiple regression analysis was to model the relationship between a predictor and a response variable after controlling the effects of other variables. To obtain the adjusted effect of a predictor on the success of the FPMT0105 course, we employed multiple logistic regression analysis, considering FPMT0105 success as the outcome variable $\left(y_{i}\right)$ and the characteristics of the students as predictors. A GPA of 2 or more in FPMT0105 was considered as success. Thus a multiple logistic regression model was fitted considering FPMT0105 success ( $y_{i}$ ) as a dichotomous response variable, with coding ' 1 ' if the $i$ th student obtained GPA 2 or more and ' 0 ' otherwise, and characteristics of the student as predictor variables $\left(x_{i}\right)$. Then $p_{i}=\operatorname{Pr}\left(y_{i}=1\right)$ can be defined as the probability of the response equal to 1 and $p_{i}$ can be modeled using logit link function where $y_{i}$ has a Bernoulli distribution. Then, we can write the logistic regression model as 


$$
\log \left[\frac{p_{i}}{1-p_{i}}\right]=\alpha+\beta_{1} x_{1 i}+\beta_{2} x_{2 i}+\ldots \ldots .+\beta_{k} x_{k i}+\varepsilon_{i},
$$

where, $k$ refers to number of predictors, $\alpha$ and $\beta$ are the intercept and slope of predictor variables and $\varepsilon$ is the error term. $\beta$ is the $\log$ of the odds ratio and $\exp (\beta)$ is the odds ratio $(\mathrm{OR})$. By definition, the odds ratio of the reference category is 1.00 . An odds ratio greater than 1.00 for a category of the predictor variable indicates a higher likelihood of the outcome in that category as compared with that of the reference category after adjusting the effects of other predictors.

\section{Results}

\section{a. Background Characteristics of Students}

Table 1 shows the distribution of students by selected background characteristics. Of the total 551 students who took the FPMT0105 course, more than sixty percent (62\%) were male and 38\% were female. The higher number of male students in our sample may be due to the fact that the sample comprised students from four different cohorts starting from 2010 to 2013 , and most of the students from older cohorts are male students. This is evident from the distribution of students by cohorts and gender (Table 1). The distribution of the students by cohort of study indicate that nearly half $(48 \%)$ of the students were from the 2012 cohort followed by the 2013 cohort (35\%). These two cohorts accounts for $83 \%$ of the total students and the rest $(17 \%)$ of the students came from the 2011 cohort (14\%) and 2010 cohort (3\%). Most of the female students were from the younger cohorts, while most of the male students were from the older cohorts. For example, almost two-thirds $(65 \%)$ of the female students were from the youngest cohort of 2013, while $61 \%$ of the male students were from the older cohort of 2012

Table 1. Percentage distribution of students by background characteristics

\begin{tabular}{|c|c|c|c|}
\hline \multirow{2}{*}{ Characteristics } & \multicolumn{2}{|c|}{ Gender } & \multirow{2}{*}{ Total $(n=551)$} \\
\hline & Female $(n=209)$ & Male $(n=342)$ & \\
\hline \multicolumn{4}{|l|}{ Gender } \\
\hline Male & - & - & 62.1 \\
\hline Female & - & - & 37.9 \\
\hline \multicolumn{4}{|l|}{ Cohort } \\
\hline 2010 & 2.4 & 4.1 & 3.4 \\
\hline 2011 & 6.2 & 18.1 & 13.6 \\
\hline 2012 & 26.3 & 60.8 & 47.7 \\
\hline 2013 & 65.1 & 17.0 & 35.2 \\
\hline \multicolumn{4}{|l|}{ College } \\
\hline Agriculture \& marine science & 14.8 & 5.6 & 9.1 \\
\hline Education & 4.8 & 1.8 & 2.9 \\
\hline Engineering & 31.6 & 56.1 & 46.8 \\
\hline Science & 48.8 & 36.5 & 41.2 \\
\hline \multicolumn{4}{|l|}{ High school math score (in \%) } \\
\hline$<70$ & - & 13.7 & 8.5 \\
\hline $70-79$ & 2.4 & 28.7 & 18.7 \\
\hline $80-89$ & 34.4 & 38.6 & 37.0 \\
\hline $90-100$ & 63.2 & 19.0 & 35.8 \\
\hline Mean score $( \pm \mathrm{SD})$ & $91.1 \pm 5.0$ & $80.6 \pm 9.5$ & $84.6 \pm 9.6$ \\
\hline$[\min , \max ]$ score & {$[77,100]$} & {$[50,98]$} & {$[50,100]$} \\
\hline \multicolumn{4}{|l|}{ High school score (in \%) } \\
\hline$<70$ & - & 1.2 & 0.7 \\
\hline $70-79$ & 0.5 & 3.8 & 2.5 \\
\hline $80-89$ & 3.3 & 73.4 & 46.8 \\
\hline $90-100$ & 96.2 & 21.6 & 49.9 \\
\hline Mean score $( \pm \mathrm{SD})$ & $93.1 \pm 2.1$ & $86.6 \pm 4.9$ & $89.1 \pm 5.0$ \\
\hline$[\min , \max ]$ score & {$[80,97]$} & {$[56,95]$} & {$[56,97]$} \\
\hline Total & 100 & 100 & 100 \\
\hline
\end{tabular}

Most of the students in our sample came from the colleges of Engineering (47\%) and of Science (41\%), accounting for $88 \%$ of the total students from these two colleges. About $9 \%$ of the students were from the College of 
Agriculture and Marine Science and a small proportion (3\%) were from the College of Education. More than half $(56 \%)$ of the male students were from the College of Engineering. On the other hand, the proportion of female students was higher from all the colleges except the College of Engineering.

Table 1 also shows the distribution of students according to their high school mathematics scores and overall high school scores out of 100. The sample data indicate that the average high school scores and the high school mathematics scores of the admitted students in SQU were $89( \pm 5.0)$ and 85( \pm 9.6$)$ respectively. The high school score ranges from 56 to 97 , while high school mathematics scores ranges from 50 to 100 . About $97 \%$ of the students had high school scores 80 and above, and 3\% students had overall high school score below 80 markswhilst more than one-third (36\%) of the students had high school mathematics scores of 90 and above, $37 \%$ had scores of 80 to 89 and $8.5 \%$ scored below 70 .

Table 2. Means and Standard Deviations of high school math score and high school score by gender.

\begin{tabular}{llll}
\hline High school performance & \multicolumn{2}{c}{ Gender } & $\begin{array}{l}\text { Test of } \\
\text { significance } \dagger\end{array}$ \\
\cline { 2 - 4 } & Male & Female & $\mathrm{t}=14.67, \mathrm{p}<0.001$ \\
\hline High school math score & $80.6( \pm 9.5)$ & $91.1( \pm 5.0)$ & $\mathrm{t}=18.88, \mathrm{p}<0.001$ \\
\hline Overall high school score & $86.6( \pm 4.9)$ & $93.1( \pm 2.1)$ &
\end{tabular}

$\dagger$ Test of significance is based on t-test, comparing two sample means of male and female students under the assumptions that the samples are independent and that they are drawn from two populations with equal variance.

The distribution of high school scores and high school mathematics scores by gender of the students indicate a huge difference between male and female scores. Female students obtained admission to SQU with both higher average high school and high school mathematics scores. For example, $96 \%$ of the female students had a high school score of 90 and above, while the corresponding figure for male students was $22 \%$. Female students had an average high school score of $93.0( \pm 2.1)$ as opposed to $87( \pm 4.9)$ for the male students, the difference being statistically significant $(\mathrm{t}$ $=18.88, \mathrm{p}<0.001)$ (Table 2). High school mathematics scores also follow a similar pattern across the gender of the students. The size of the effects of gender on high school mathematics and overall high school score, measured by etasquared $\left(\eta^{2}=\right.$ between SS/total SS), indicates that gender explained $39.4 \%$ of the variation in high school mathematics scores and $28.2 \%$ in overall high school scores respectively.

Table 3. Percentage distribution of grades in FPMT0105 by gender of students.

\begin{tabular}{cllll}
\hline \multirow{2}{*}{ Letter grade } & \multicolumn{2}{c}{ Gender } & Total & \multirow{2}{*}{ Number } \\
\cline { 2 - 4 } & Female & Male & & \\
\hline A & 3.83 & 1.17 & 2.18 & 12 \\
\hline A- & 7.66 & 0.88 & 3.45 & 19 \\
\hline B + & 14.83 & 2.05 & 3.09 & 17 \\
\hline B & 16.27 & 2.63 & 6.90 & 38 \\
\hline B- & 7.18 & 0.58 & 7.80 & 43 \\
\hline C + & 11.48 & 9.65 & 6.90 & 38 \\
\hline C & 10.05 & 10.53 & 10.34 & 57 \\
\hline C- & 12.44 & 3.51 & 10.34 & 57 \\
\hline D+ & 8.13 & 29.53 & 13.25 & 73 \\
\hline D & 6.70 & 17.25 & 21.42 & 118 \\
\hline F & 1.44 & 22.22 & 14.34 & 79 \\
\hline Total & 100.0 & 100.0 & 100.00 & 551 \\
\hline
\end{tabular}

\section{b. Performance in FPMT0105 and its Covariates}

Students' performances in the FPMT0105 course were measured by the aggregate scores obtained in quizzes, homeworks, tests and the final examination. The aggregate scores, evaluated out of 100, were converted into letter grades and the grade point average (GPA) in a 4-point scale. The results are presented in Table 3 by gender. Overall, $5.6 \%$ of the students obtained grade A, $17.8 \%$ grade B, $27.6 \%$ grade C, $34.7 \%$ grade D and $14 \%$ of students failed (obtained grade F) in the course (Figure 1). The data indicate that half (49\%) of the students obtained below grade $\mathrm{C}$ which in terms of grade point average is below 2, indicating a very poor performance of the students in the mathematics foundation course. The overall grade point average in FPMT0105 was 1.66.

Table 4 presents the results of differential analysis and analysis of variance (ANOVA) showing differential effects of some selected factors on mean GPA in FPMT0105. Gender of the students shows a significant differential effect on mean GPA in FPMT0105. Female students performed better than male students. The mean GPA of female students was two times higher than of male students (2.41 vs. 1.20). Cohort of the students shows significant positive association with the mean GPA in FPMT0105. Recent cohorts performed better than their older counterparts. For example, the mean GPA was 2.55 for the 2013 cohort compared to 0.52 for the 2010 cohort. FPMT0105 performance varies significantly with the college of study of the students. Students from the College of Agriculture and Marine 
Science showed the lowest performance (mean GPA 1.27), while the students from the College of Education exhibited the highest performance (mean GPA 2.32). High school mathematics scores and overall high school scores showed significant positive association with the performance in FPMT0105. For example, the mean GPA was 0.92 for the students with high school scores less than 70, and the corresponding figure for the students with high school scores 90 100 was 2.24 .

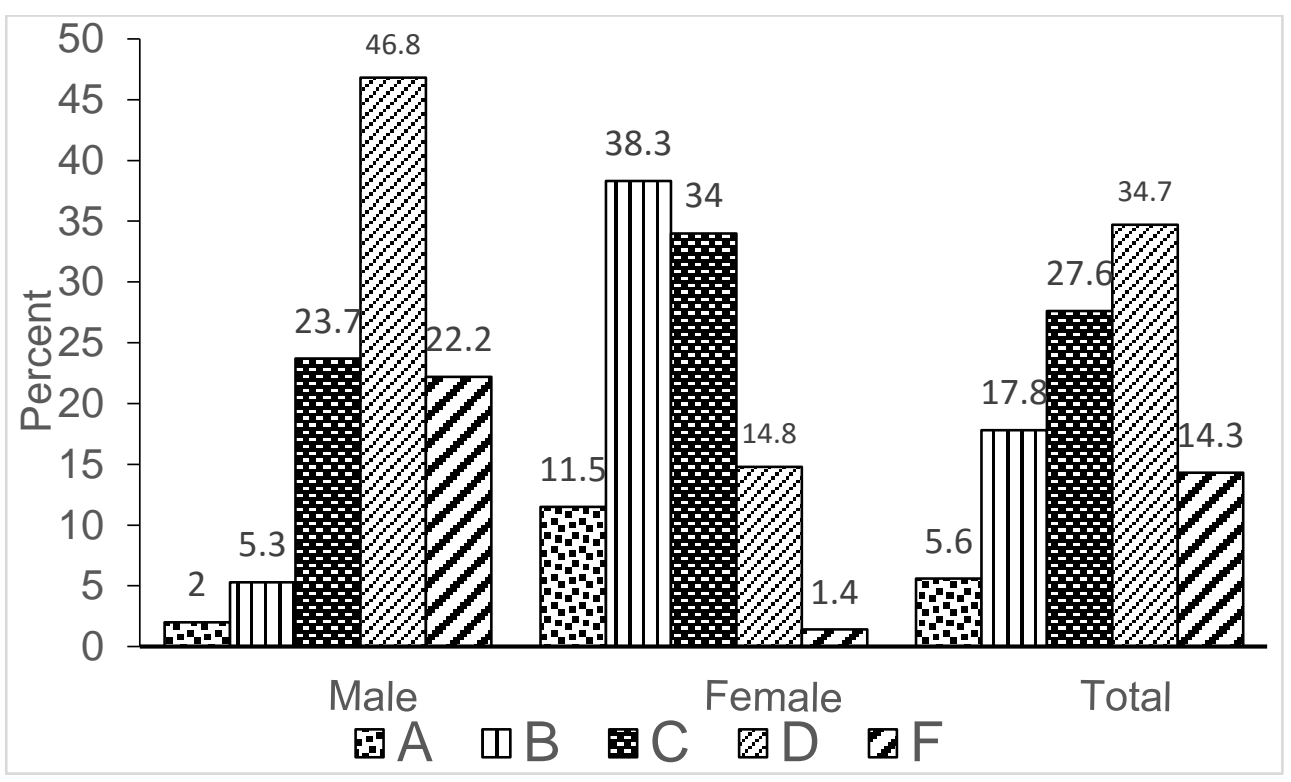

Figure 1. Distribution of grade in FPMT0105 by gender of students

Table 4. Mean GPA with $95 \%$ confidence interval (95\% CI) for the mathematics foundation course (FPMT0105) by characteristics of students.

\begin{tabular}{lllll}
\hline Characteristics & Mean GPA & \multicolumn{2}{c}{ 95\% CI } & F ratio and p-value \\
\hline Total & 1.66 & 1.57 & 1.75 & \\
\hline Gender & & & & $250.12, \mathrm{p}<0.001$ \\
\hline$\quad$ Male & 1.20 & 1.11 & 1.29 & \\
\hline$\quad$ Female & 2.41 & 2.29 & 2.53 & \\
\hline Cohort & & & & $166.79, \mathrm{p}<00.1$ \\
\hline 2010 & 0.52 & 0.24 & 0.79 & \\
\hline 2011 & 0.57 & 0.40 & 0.73 & \\
\hline 2012 & 1.39 & 1.30 & 1.48 & \\
\hline 2013 & 2.55 & 2.45 & 2.67 & \\
\hline College & & & & \\
\hline Agriculture \& marine science & 1.27 & 1.06 & 1.48 & \\
\hline Education & 2.32 & 1.74 & 2.89 & \\
\hline Engineering & 1.84 & 1.71 & 1.97 & \\
\hline Science & 1.49 & 1.35 & 1.63 & \\
\hline High school mathematics score (in & & & & \\
\%) & & & & \\
\hline$<70$ & 0.61 & 0.43 & 0.79 & \\
\hline $70-79$ & 1.04 & 0.90 & 1.17 & \\
\hline $80-89$ & 1.56 & 1.44 & 1.68 & \\
\hline $90-100$ & 2.33 & 2.19 & 2.48 & \\
\hline Overall high school score (in \%) & & & & $79.83, \mathrm{p}<0.001$ \\
\hline$<70$ & 0.92 & -0.78 & 2.63 & \\
\hline $70-79$ & 1.13 & 0.79 & 1.47 & \\
\hline $80-89$ & 1.08 & 0.99 & 1.17 & \\
\hline $90-100$ & 2.24 & 2.12 & 2.35 & \\
\hline & & & \\
\hline
\end{tabular}




\section{MAZHARUL ISLAM ET AL}

\subsection{Predictor of FPMT0105 Success}

To examine whether there is a significant relationship between FPMT0105 performance and high school performance and other characteristics of students, we first employed correlation analysis. The results are presented in Table 5 .

The results indicate that all the correlation coefficients between FPMT0105 scores and the given set of predictors, except college of study, were found positive and significant at 0.01 level. Overall high school score, high school mathematics score and gender of student have moderate positive correlation with FPMT0105 score and are close to each other. Cohort of study shows the highest correlation coefficient with FPMT0105 score. The R-squared statistic indicates that cohort of study explained $45 \%$ of the variation in performance on the FPMT0105 course. High school mathematics score explained $33 \%$ of the variation in performance on the FPMT0105 course, while overall high school score explained $29.5 \%$ of the variation for this course. This indicates that high school mathematics scores have slightly higher predictive value in explaining variation in FPMT0105 performance than overall high school scores.

Table 5. Correlation coefficients and R-squared statistics for FPMT score and gender, high school mathematics score, overall high school score, and cohort of students.

\begin{tabular}{lll}
\hline & Correlation coefficient $(\mathrm{r})$ & R-squared statistic \\
\hline High school math score & $0.575^{* *}$ & 0.331 \\
\hline High school total score & $0.543^{* *}$ & 0.295 \\
\hline Gender & $0.548^{* *}$ & 0.300 \\
\hline College of study & -0.037 & 0.001 \\
\hline Cohort of study & $0.674^{* *}$ & 0.454 \\
\hline
\end{tabular}

** Correlation is significant at the 0.01 level (2-tailed).

Table 6. Multiple logistic regression analysis of success in mathematics foundation course showing the adjusted odds ratio of factors effecting the success.

\begin{tabular}{|c|c|c|c|c|c|}
\hline \multirow[t]{2}{*}{ Factors } & \multirow[t]{2}{*}{ B } & \multirow[t]{2}{*}{ Odds ratio } & \multicolumn{2}{|c|}{ 95\% CI for Odds ratio } & \multirow[t]{2}{*}{ P-value } \\
\hline & & & Lower & Upper & \\
\hline Cohort & & & & & .000 \\
\hline $2010 / 2011$ & reference & & & & \\
\hline 2012 & 1.71 & 5.53 & 1.78 & 17.78 & .003 \\
\hline 2013 & 3.39 & 29.67 & 8.98 & 99.05 & .000 \\
\hline \multicolumn{6}{|l|}{ Gender } \\
\hline Female & 1.40 & 4.05 & 1.62 & 10.18 & .003 \\
\hline Male & reference & & & & \\
\hline College & & & & & .372 \\
\hline Agriculture \& Marine science & -.640 & .52 & .18 & 1.46 & .221 \\
\hline Engineering & .072 & 1.08 & .03 & 1.14 & .301 \\
\hline Education & .340 & 1.40 & .63 & 2.10 & .401 \\
\hline Science & reference & & & & \\
\hline High school mathematics score & .098 & 1.10 & 1.03 & 1.16 & .001 \\
\hline Overall high school score & .034 & 1.03 & 0.89 & 1.07 & .705 \\
\hline Constant & -13.388 & .000 & & & .001 \\
\hline
\end{tabular}

The correlation analysis, however, shows the relationship between two variables without controlling the effects of other variables. To obtain the adjusted effect of a predictor on the success of FPMT0105 we employed multiple logistic regression analysis. Table 6 presents the results of multiple logistic regression analysis. Multiple logistic regression analysis identified high school mathematics score, cohort and gender of students as significant predictors of mathematics foundation course (i.e. FPMT0105) success. The result indicates that one unit increase in high school mathematics score increases the odds of success in FPMT0105 by 1.10 times $(\mathrm{OR}=1.10 ; 95 \% \mathrm{CI}=1.03-1.16)$. Cohort appeared as the most significant predictor of success in the foundation mathematics course. The older the cohort, the worse the performance in the mathematics foundation course. For example, students from the recent cohort of 2013 were 30 times more likely to be successful in their mathematics foundation course than those from the older cohort of 2010/2011 (OR=29.67; 95\%CI=8.98-99.05). Female students were 4 times more likely to perform better than male students in their mathematics foundation course $(\mathrm{OR}=4.05 ; 95 \% \mathrm{CI}=1.62-10.18)$.

\section{Discussion}

The analysis of background characteristics of the sampled students revealed that among the admitted students in SQU, female students had significantly higher average scores in both high school mathematics and overall high school 
scores than male students. For example, the high school scores of male students ranges from 56 to 96 with an average of 86.6, while for female students it ranges from 80 to 97 with an average of 93 . This indicates that many boys with relatively less qualification than girls were admitted in the university. This might be one of the reasons why boys are consistently underperforming in SQU than girls. One recent study has documented that female students in SQU are outperforming boys [40]. The higher performance of girls than boys in almost all levels of education is, however, a global phenomenon in recent times [41-43]. Oman is not an exception. Since high school performance is the only requirement for entry into SQU and females are doing better than male students at high school level, then there should be more female students than males in SQU in recent time. However, if we look at the overall gender ratio of the admitted students over the years, there is a more or less 50:50 ratio of male-female students in SQU. This raises a question: does the admission process favor boys with lesser high school scores than girls for admission to SQU for the sake of maintaining a 50:50 ratio of boys and girls among the admitted students? However, we do not have any supporting documentation to answer this questions. It is worth mentioning here that enrolling under-qualified students in a university leads to a misuse of resources, particularly in a public university like SQU where education is free. Besides, failing to select the most able and motivated candidates might have serious negative impacts on a discipline as well as on the university in general in the long run. Our analysis reveals a very poor performance by the students in the mathematics foundation course (i.e. FPMT0105) as their mean GPA was 1.66 and more than half (59\%) of the students obtained a GPA of less than 2 (i.e. below grade C); of these 14\% failed and 35\% obtained grade D, although $97 \%$ of these students entered SQU with an overall high school score of 80 and above, and $91 \%$ with a high school mathematics score of 70 and above. This is a very dismal scenario regarding the best students of the nation, as SQU is the only public university and the premier institution for higher education in Oman, which attracts the best students from all over the country. The results indicate that the Omani high school curricula, particularly in mathematics, are falling short in preparing students for success in their postsecondary education. Analyzing data from the high school and beyond, Adelman [16] found that the high school curriculum exerted a more powerful influence on bachelor's degree attainment than did test scores, high school class rank, and high school grade point average. It has been argued that rigorous high school courses including mathematics help prepare students for the college learning environment and enhance their ability to succeed in higher education $[16,44]$. Our findings indicate significant differential effects of gender on performance in the mathematics foundation course. Female students had significantly higher mean GPA (2.41) than male students (1.20). Nearly two-thirds (73\%) of the male students obtained less than C grade, while the figure was $29 \%$ for the female students. The proportion of students with F grade was also significantly higher for male students than female students $(22 \%$ vs. $1 \%)$. These students with less than $\mathrm{C}$ grade are at higher risk of dropping out from the University or repeating the course, lengthening their academic life and thus becoming a burden on the family, society and the university administration. The differential analysis indicates unadjusted significant effects of cohort, college of study, high school math score and overall high school score on mathematics foundation course performance. Correlation analysis also shows significant correlation between mathematics foundation course performance and gender, cohort, high school mathematics score and overall high school scores. Correlation analysis also shows that high school mathematics scores have higher predictive value than overall high school scores. High school mathematics score explained $33 \%$ of the variation in performance on the mathematics foundation course, while high school total score explained $29.5 \%$ of the variation in mathematics foundation course score. Multivariate analysis identified gender, cohort, and high school math scores as the significant predictors of mathematics foundation course performance. Overall high school score becomes an insignificant predictor in multivariate analysis. This is mainly because the effect of high school mathematics scores mediate overall high school scores. The findings of this study correspond with those of many others which have found that high school mathematics performance is a significant predictor of college mathematics success [17, 18, 23, 45]. Ma [46] showed that students exposed to advanced mathematics courses at the middle and junior high school level had high mathematics achievement in subsequent academic life.

\section{Conclusion}

The study findings reveal a very gloomy scenario of performance in the mathematics foundation course in SQU, particularly among the male students. The results indicate that many students are entering post-secondary education with little preparation and are thus unable to cope with the college curricula, although they have a very good grade in high school. This may be due either to high schools giving inflated scores to their students, or to the contents of the high school mathematics curriculum falling far short of college standard. In order to improve the situation, high school curricula needs to be aligned with college standards. Policy makers should give due attention to this matter. The findings of this study suggest the need for more careful admission decisions to improve the success in the foundation program. Both gender and high school performance should be taken into consideration in an equitable manner to have fairer admission decisions. The findings further suggest that the admission authority should give more attention not only to overall high school scores but also to high school mathematics scores, particularly for admission into science based colleges in SQU, because these two predictor variables have higher correlation coefficients with the mathematics foundation course performance and thus greater predictive power of success. 


\section{MAZHARUL ISLAM ET AL}

\section{Acknowledgement}

The authors would like to thank the Statistics and Technical Support department of Deanship of Admission and Registration office of SQU for providing relevant data for this study. Special thanks goes to Mr. Khamis Al-Abri and Mr. Haitham Al-Nahwi for their continuous support and prompt response in providing required data. The views expressed herein are solely those of the authors and do not necessarily reflect the views of any institution or organization.

\section{References}

1. Schofer, E. and Meyer. Journal of the worldwide expansion of higher education in the twentieth century. American Sociological Review, 2005, 70, 898-920.

2. Clancy, P. Measuring access and equity from a comparative perspective. In: Eggins, H. (Ed.). Access and Equity: Comparative Perspectives. Rotterdam: Sense Publishers, 2010, 69-102.

3. Altbach, P.G. and Knight. Journal of the internationalization of higher education: Motivation and realities. Journal of Studies in International Education, 2007, 11(3), 290-305.

4. Hourigan, M. and O'Donoghue. Journal Mathematical under-preparedness: The influence of the pre-tertiary mathematics experience on students' ability to make a successful transition to tertiary level mathematics courses in Ireland. International Journal of Mathematics Education in Science and Technology, 2007, 38(4), 461-476.

5. Rylands, L. and Coady, C. Performance of students with weak mathematics in first-year mathematics and science. International Journal of Mathematical Education in Science and Technology, 2009, 40(6), 741-753.

6. Al-Ghanboosi, S.S. and Ayedh, A.A.A. Student dropout trends at Sultan Qaboos University and Kuwait University: 2000-2011. College Student Journal, 2013, 47, 499-506.

7. Oman Accreditation Council. Quality Audit Manual-Institutional Accreditation: Stage 1. Sultanate of Oman: Oman Accreditation Council. Ministry of Information \#2008/87, 2008. Also available online

at www.oac.gov.om/institution/audit/

8. Carroll, M.I., Razvi. S. and Goodliffe, T. Using foundation program academic standards as a quality enhancement tool, a paper for INQAAHE, 2009. http://www.oac.gov.om/qe/oqn

9. Al-Mamari, A.S. General Foundation Program in Higher Education Institutions in Oman National Standards: Implementation and Challenges. Paper presented in the Oman Quality Network Regional Conference 20-21 February, 2012, Ministry of Higher Education, Muscat.

10. Travers, R.M.W. Significant research on the prediction of academic success. In W.T. Donahue, C.H. Coomb, and R.M.W. Travers (eds.), The Measurement of Student Adjustment and Achievement, 1949, pp. 147-190. Ann Arbor: University of Michigan Press.

11. Fishman, J.A. Supplement to College Board Scores, No. 2. New York: College Entrance Examination Board, 1957.

12. Cabrera, A.F., Nora, A. and Castañeda, M.B. College persistence: structural modeling of an integrated model of student retention. Journal of Higher Education, 1993, 64, 123-139.

13. Wolfe, R.N. and Johnson S.D. Personality as a predictor of college performance. Educational and Psychological Measurement, 1995, 55(2), 177-185.

14. Eimers, M.T. and Pike, G.R. Minority and nonminority adjustment to college: differences or similarities? Research in Higher Education, 1997, 38, 77-97.

15. Noble, J. and Sawyer, R. Alternative methods for validating admission and course placement criteria. AIR

Professional File, No., 1997, 63, 1-9.

16. Adelman, C. Answers in the tool box: Academic intensity, attendance patterns, and bachelor's degree attainment. Washington, DC: U.S. Department of Education, Office of Educational Research and Improvement, 1999.

17. Bridgeman, B., McCamley-Jenkins, L., and Ervin, N. Predictions of freshman grade point average from the revised and recentered SAT I: Reasoning Test (College Board Rep. No. 2000-1). New York: College Entrance Examination Board, 2000.

18. Snyder, V., Hackett, R.K., Stewart, M. and Smith, D. Predicting academic performance and retention of private university freshmen in need of developmental education. Research and Teaching in Developmental Education, 2003, 19(2), 17-28.

19. Cohn, E., Cohn, S., Balch, D. and Bradley, J. Determinants of undergraduate GPAs: SAT scores, high-school GPA and high-school rank. Economics of Education Review, 23, 577-586.

http://dx.doi.org/10.1016/j.econedurev.2004.01.001, 2004

20. Pentages, T.J. and Creedon, C.F. Studies of college attrition: 1950-1975. Review of Educational Research, 1978, 48, 49-101.

21. Kappe, R. and Flier, H.V.D. Predicting academic success in higher education: what's more important than being smart? European Journal of Psychology of Education, 2012, 27(4), 605-619.

22. Clercq, M.D., Galand, B., Dupont, S. and Frenay, M. Achievement among first-year university students: an integrated and contextualized approach. European Journal of Psychology of Education, 2013, 28(3), 641-662. http://dx.doi.org/10.1007/s10212-012-0133-6. 
23. Islam, M.M. and Al-Ghasani, A. Predicting college math success: do high school performance and gender matter? evidence from Sultan Qaboos University in Oman. International Journal of Higher Education, 2015, 4(2), 67-80.

24. Kowarsky, J., Clatfelter, D. and Widaman, K. Predicting university grade-point average in a class of University of California freshmen: an assessment of the validity of GPA and test scores as indicators of future academic performance. Institutional research paper. Oakland, CA: University of California Office of the President, 1998.

25. Betts, J.R. and Morrell, D. The determinants of undergraduate grade point average. Journal of Human Resources, 1999, 34(2), 268-293. http://dx.doi.org/10.2307/146346.

26. Camara, W.J. and Echternacht, G. The SAT[R] I and High School Grades: Utility in Predicting Success in College. (Report No. CB-RN-10). New York, NY: College Entrance Examination Board, 2000.

27. Fleming, J. Who will succeed in college? When the SAT predicts black students' performance. Review of Higher Education, 2002, 25(3), 281-296.

28. Zheng, J.L., Saunders, K.P., Shelley II, M.C. and Whalen, D.F. Predictors of academic success for freshmen residence hall students. Journal of College Student Development, 2002, 43(2), 267-283.

29. Geiser, S. and Santelices, M.V. Validity of high-school grades in predicting student success beyond the freshman year: high-school record vs. standardized tests as indicators of four-year college outcomes. University of California, Berkeley, 2007.

30. Pascarella, E.T. and Terenzini, P.T. How College Affects Students: Findings and Insights from Twenty Years of Research. San Francisco: Jossey-Bass, 1991.

31. Lee, V.E., Bryk, A.S. and Smith, J.B. The organization of effective secondary schools. In L. Darling-Hammond (ed.), Review of Research in Education, 1993, 19, 171-267.

33. Wilhite, P., Windham, B. and Munday, R. Predictive effects of high school calculus and other variables on achievement in fist-semester college calculus course. College Student Journal, 1998, 32(4), 610-618.

32. Williford, L.E. The freshman year: How do personal factors influence academic success and persistence? 1996 SAIR Annual Report: Charting the Course in a Changing Environment. Mobile, AL: Southern Association for Institutional Research and Southern Region of the Society for College and University Planning, 1996.

34. Schneider, B.L., Kirst, M. and Hess, F.M. Strategies for success: high school and beyond. Brookings Papers on Education Policy, 2003, 6, 55-93.

35. Adelman, C., Daniel, B. and Berkovits, I. Postsecondary attainment, attendance, curriculum, and performance: Selected results from the NELS:88/2000 postsecondary education transcript study (PETS), 2003.

36. Adelman, C. The toolbox revisited: paths to degree completion from high school through college. Washington, DC: U.S. Department of Education, 2006. Retrieved from http://www2.ed.gov/rschstat/research/pubs/toolboxrevisit/ toolbox.pdf

37. Russell, Bertrand. A History of Western Philosophy, George Allen and Unwin Ltd., London 1945, ISBN 0-41532505-6, 1945.

38. Bressoud, D.M. Why do we teach calculus? American Mathematical Monthly, 1992, 99, 615-617.

39. Pearson, K. On a new method for determining the correlation between a measured character A, and a character B, Biometrika, 1909, 7, 96-105.

40. Islam, M.M. Factors influencing the academic performance of undergraduate students in Sultan Qaboos University in Oman. Journal of Emerging Trends in Educational Research and Policy Studies, 2014, 5(4), 396-404.

41. Azen, R., Bronner, S. and Gafni, N. Examination of gender bias in university admissions. Applied Measurement in Education, 2002, 15, 75-94.

42. Chambers, E.A. and Schreiber, J.B. Girl's academic achievement: varying associations of extracurricular activities. Gender and Education, 2004, 16(3), 327-346.

43. Van Houtte, M. Why boys achieve less at school than girls: The difference between boys' and girls' academic culture. Educational Studies, 2004, 30, 159-173.

44. Bourquin, S.D. The relationship among math anxiety, math self-efficacy, gender, and math achievement among college students at an open admissions commuter institution. Dissertation Abstracts International, Section A. Humanities and Social Sciences, 1999, 60(3-A), 0679.

45. Kuncel, N.R., Credé, M. and Thomas, L.L. A comprehensive meta-analysis of the predictive validity of the Graduate Management Admission Test (GMAT) and undergraduate grade point average (UGPA). Academy of Management Learning and Education, 2007, 6, 51-68.

46. Ma, X. A longitudinal assessment of antecedent course work in mathematics and subsequent mathematical attainment, The Journal of Educational Research. 2000, 94(1), 16-28.

Received 11 January 2017

Accepted 25 September 2017

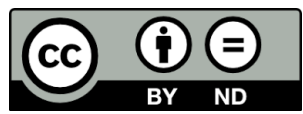

